\title{
Adherence to pediatric asthma guidelines in the emergency department: A survey of knowledge, attitudes and behaviour among health care professionals
}

\author{
Sanjit K Bhogal MSc${ }^{1}$, Jean Bourbeau MD ${ }^{1,2}$, David McGillivray MD ${ }^{3}$, Andrea Benedetti PhD ${ }^{1,2}$ \\ Susan J Bartlett PhD ${ }^{4}$, Francine M Ducharme MD MSc FRCPC FAAP1,5
}

\begin{abstract}
SK Bhogal, J Bourbeau, D McGillivray, A Benedetti, SJ Bartlett, FM Ducharme. Adherence to pediatric asthma guidelines in the emergency department: A survey of knowledge, attitudes and behaviour among health care professionals. Can Respir J 2010;17(4):175-182.
\end{abstract}

BACKGROUND: Despite strong evidence for using clinical care pathways to manage acute pediatric asthma, adherence remains suboptimal. OBJECTIVES: To elicit information from health care professionals regarding their knowledge, attitudes and use of a care pathway for acute childhood asthma.

METHODS: A cross-sectional, self-administered survey of physicians, nurses and respiratory therapists who worked in the emergency department at the Montreal Children's Hospital (Montreal, Quebec) from August to December 2007 was conducted. The survey assessed knowledge, attitude toward and agreement with the care pathway, as well as its use four years after its implementation.

RESULTS: Of the 128 health care professionals surveyed, 72 (56\%) responded. Of these, $99 \%$ reported being familiar with the pathway, more than $90 \%$ agreed with its use for mild and moderate asthma, while $79 \%$ agreed with its use for severe asthma. For $99 \%$ of health care professionals, the advantages of using the pathway outweighed the disadvantages; however, $64 \%$ admitted to making variations to the pathway. Although $92 \%$ of respondents reported that they were quite comfortable with using the asthma severity Pediatric Respiratory Assessment Measure, only 53\% and $36 \%$ correctly identified the severity score cut-offs for moderate and severe asthma, respectively. Seventeen per cent of respondents underestimated the delay of onset of action of oral corticosteroids, while $36 \%$ of physicians incorrectly believed that a higher than necessary dose was recommended for ipratropium bromide.

CONCLUSIONS: Results of the survey confirmed that the health care professionals queried had a positive attitude toward the pediatric asthma care pathway. Knowledge gaps and the balance between standardization versus individualization of care may be key elements to explain suboptimal adherence to the pathway.

Key Words: Barriers; Clinical practice guidelines; Emergency; Pediatric asthma; Survey

linical practice pathways for the management of acute pediatric asthma are derived from high-quality randomized controlled trials and meta-analyses $(1,2)$. The implementation of asthma pathways in the emergency department (ED) have frequently - but not uniformly - demonstrated reduced length of stay in the ED, decreased risk of hospital admissions,

\section{Respect des directives sur l'asthme infantile dans les urgences : Enquête sur les connaissances, les attitudes et la pratique des professionnels de la santé}

HISTORIQUE : Malgré des preuves solides à l'appui des directives de pratique clinique pour la prise en charge de l'asthme infantile aigu, leur utilisation reste sous-optimale.

OBJECTIF : Faire le point sur les connaissances, les attitudes et l'application des lignes directrices dans l'asthme infantile aigu chez les professionnels de la santé.

MÉTHODE : Les auteurs ont procédé à un sondage transversal autoadministré auprès des médecins, infirmières et inhalothérapeutes des urgences de l'Hôpital pour enfants de Montréal (Montréal, Québec) d'août à décembre 2007. Le sondage visait à vérifier dans quelle mesure ils connaissaient les lignes directrices, comment ils les percevaient et les acceptaient et s'ils les utilisaient, quatre ans après leur mise en œuvre. RÉSULTATS : Parmi les 128 professionnels de la santé interrogés, 72 (56\%) ont répondu. Parmi eux, $99 \%$ se sont dit au courant des lignes directrices, plus de $90 \%$ étaient d'accord avec leur utilisation dans l'asthme de léger à modéré, tandis que $79 \%$ se disaient d'accord avec leur utilisation dans l'asthme grave. Pour $99 \%$ des professionnels de la santé, les avantages des lignes directrices l'emportaient sur leurs inconvénients. Toutefois, $64 \%$ ont admis y apporter des modifications. Bien que $92 \%$ des répondants aient dit se sentir assez à l'aise avec l'outil de mesure de la gravité de l'asthme infantile, seulement $53 \%$ et $36 \%$ respectivement ont correctement reconnu les seuils de classification de l'asthme modéré et grave. Dix-sept pour cent des répondants ont sous-estimé le temps qu'il faut aux corticostéroïdes oraux pour commencer à agir, tandis que $36 \%$ des médecins ont cru à tort qu'une dose plus forte que nécessaire était recommandée dans le cas du bromure d'ipratropium.

CONCLUSIONS : Les résultats du sondage ont confirmé que les professionnels de la santé interrogés avaient une attitude positive à l'endroit des lignes directrices pour l'asthme infantile. Leur application sous-optimale pourrait s'expliquer notamment par un manque de connaissances et par l'équilibre recherché entre la standardisation et l'individualisation de l'approche thérapeutique.

and reduced costs without an increased rate of readmission (3-6). To improve care, an acute pediatric asthma pathway has been implemented at the Montreal Children's Hospital (Montreal, Quebec) since 2003 (7). While the pathway significantly reduces the risk of hospital admission and length of active treatment (8), less than one-half of children with moderate and severe asthma

${ }^{1}$ Department of Epidemiology, Biostatistics and Occupational Health, Faculty of Medicine, McGill University; ${ }^{2}$ Respiratory Epidemiology and Clinical Research Unit, Montreal Chest Institute; ${ }^{3}$ Department of Pediatrics, Montreal Children's Hospital of the McGill University Health Centre; ${ }^{4}$ Faculty of Medicine, McGill University; ${ }^{5}$ Research Centre, Centre hospitalier universitaire Sainte-Justine and Department of Pediatrics, University of Montreal, Montreal, Quebec

Correspondence: Dr Francine M Ducharme, Department of Pediatrics, Centre hospitalier universitaire Sainte-Justine, 3175 Côte-Ste-Catherine, Montreal, Quebec H3T 1C5. Telephone 514-345-4931 ext 4398, fax 514-345-4822, e-mail francine.m.ducharme@umontreal.ca 
receive all recommended treatments within the recommended time frame $(7,8)$ - a figure that is similar to other institutions $(4,9,10)$.

Critics argue that clinical practice pathways may oversimplify medical decision making, and restrict both the individualization of care and the freedom of physicians and other health care providers to act according to their previous experiences (11-15). These negative perceptions may act as barriers to implementation (16). In the nonacute care setting in the United States, lack of agreement with guidelines and poor self-efficacy for dosing and/or recognizing contraindications have been identified as important barriers to prescribing inhaled corticosteroids as recommended by the Guidelines of Diagnosis and Management of Asthma (14,17). To our knowledge, barriers to implementation of asthma pathways in the acute care setting have not been identified.

The objective of the present study was twofold. First, we administered a survey to emergency health care profesionals that sought to assess the knowledge of and attitudes toward the selfreported use of our care pathway for childhood asthma four years after implementation. Second, we explored potential differences in barriers between attending physicians, nurses and respiratory therapists involved in acute asthma care.

\section{METHODS}

\section{Study design}

An anonymous, self-administered survey was conducted in the ED of the Montreal Children's Hospital of the McGill University Health Centre, a tertiary care pediatric hospital. The study received approval by the Scientific Review and Research Ethics Boards, and participants provided informed consent.

\section{Participants}

Health care professionals were eligible for inclusion in the present study if they had worked in the ED between August and December 2007 as an attending physician, ED fellow, nurse or respiratory therapist. There were no exclusion criteria. No honorarium was offered for participation in the study.

\section{The asthma care pathway}

The acute care pathway is derived from evidence-based guidelines (18-20). The severity-specific pathway is embedded in the ED order sheet, serving as a written and unavoidable reminder of the guidelines (7). Because most children are unable to undergo spirometry, recommendations are based on asthma severity assessed at triage using the Pediatric Respiratory Assessment Measure (PRAM) (21). Briefly, this validated 12 -point clinical score evaluates scalene retraction, suprasternal retraction, air entry, wheezing and oxygen saturation. Scores of 1 to 4,5 to 8 , and 9 to 12 were deemed to be indicative of mild, moderate and severe asthma exacerbations, respectively. The minimal care to be provided as outlined by the pathway is as follows: for mild asthma, at least one nebulization of salbutamol; for moderate asthma, at least one nebulization of salbutamol and one dose of systemic corticosteroids; and for severe asthma, three nebulizations of salbutamol and ipratropium bromide, and one dose of systemic corticosteroids. All medications are to be administered within $60 \pm 15 \mathrm{~min}$ of triage (7).

\section{Survey}

The survey was developed by the study authors to query knowledge, attitudes and self-reported behaviour related to the care pathway. Questions designed to assess knowledge and attitudes tapped into each of six internal barriers to adherence as described in the Cabana et al (13) and Espeland and Baerheim (22) studies, namely, knowledge, agreement, outcome expectancy (the expectation that following the pathway will lead to a positive health impact), process expectancy (the expectation that following the pathway will lead to better process of care), feeling expectancy (the expectation that following the pathway will lead to feelings of satisfaction) and self-efficacy (the belief that one can actually perform a behaviour). The survey also queried health care professionals' use of the pathway. The survey concluded with two open-ended questions asking respondents what prevented them most from following the treatment plan and adhering to the recommended timeline for treatment administration. Information, including professional status (physician, nurse or respiratory therapist), shift coverage in the ED and number of years worked in the ED were documented for each respondent.

\section{Procedures}

Anonymous surveys were distributed to physicians and nurses at the beginning of their shift in the ED, or at their office for physicians who worked in the ED part time or occasionally. The director of respiratory therapy services distributed and collected surveys of all eligible respiratory therapists. Approximately $5 \mathrm{~min}$ to $10 \mathrm{~min}$ was needed to complete the survey. Responses were entered into a database using automated data collection TELEform software (Cardiff Software Inc, USA).

\section{Statistical analysis}

The proportion of respondents endorsing each response option was reported with a corresponding $95 \%$ CI. Using the electronic ED log, the proportion of children treated was determined by dividing the number of children treated by the surveyed physicians by the total number of children presenting to the ED with acute asthma during the three-month study period. Because of the similarity of roles, the responses of nurses and respiratory therapists were combined into the allied health care professional group, which were compared with that of physicians using the $\chi^{2}$ test or Fisher's exact test for categorical variables and the Wilcoxon-Mann-Whitney test for continuous variables. No correction was made to compensate for multiple comparisons. All statistical tests were performed as two-tailed tests. The data were analyzed using SAS version 9.1 (SAS Institute Inc, USA).

\section{RESULTS}

Of the 128 eligible emergency health care professionals, 47 physicians, 18 nurses and seven respiratory therapists completed the survey, yielding an overall response rate of 56.3\% (Figure 1). There were no significant differences between respondents and nonrespondents with respect to sex, health care profession or ED shift coverage. The 47 surveyed physicians attended to $77 \%$ of all children who presented with acute asthma during the 12-week study period. As expected, a significantly higher percentage of allied health care professionals than attending physicians were women (96\% versus $55 \% ; \mathrm{P}<0.001)$ and reported working fulltime in the $\mathrm{ED}(80 \%$ versus $26 \% ; \mathrm{P}<0.001)$. 


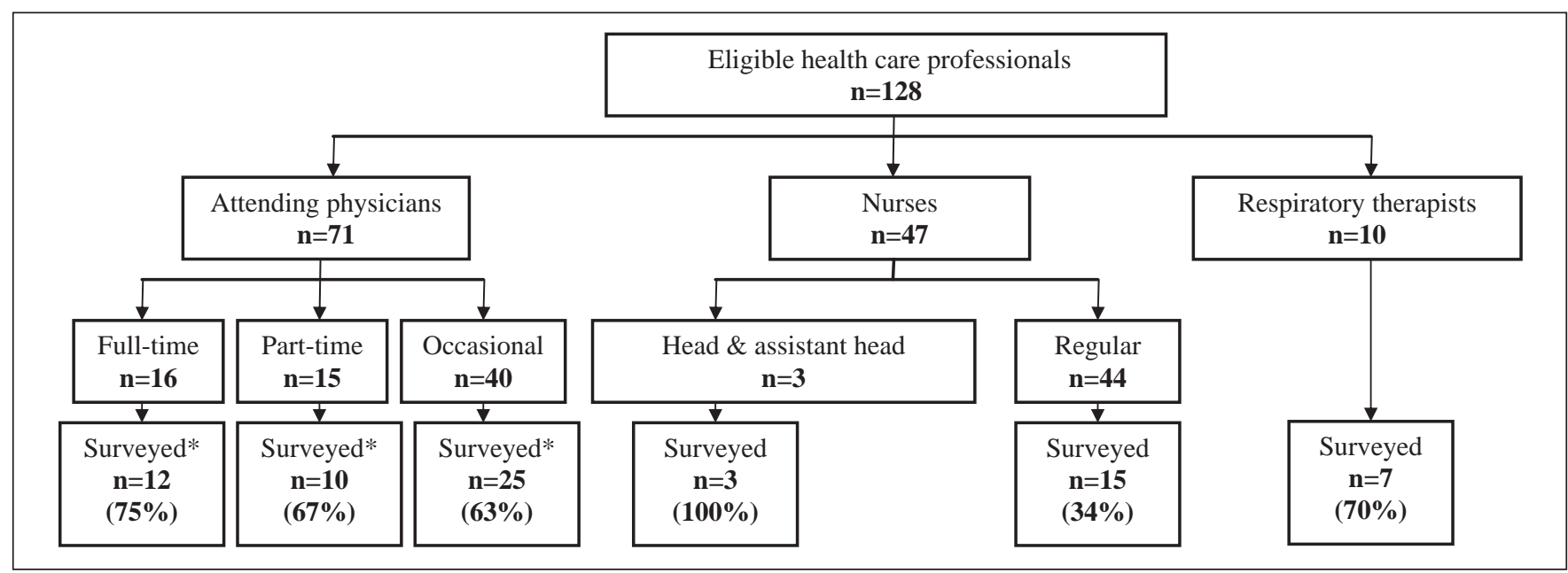

Figure 1) Flow chart of health care professionals surveyed. *Surveyed full-time, part-time and occasional physicians attended to $37 \%, 10 \%$ and $30 \%$ of children with acute asthma, respectively, for a total of $77 \%$ during the study period

Results pertaining to knowledge of the care pathway are presented in Table 1. Although 99\% of the health care professionals surveyed reported being familiar with the severity-specific pathway, only $53 \%$ correctly reported the PRAM cut-off value for moderate asthma, and only $36 \%$ correctly reported the cutoff for severe asthma; in the latter group, the majority (61\%) used a lower PRAM cut-off than indicated on the pathway. While the overwhelming majority properly identified relief of airway inflammation as the mechanism of action of oral prednisone, $17 \%$ underestimated the time to onset of action (ie, believed it was earlier). For ipratropium bromide, 32\% incorrectly believed it relieved airway inflammation, and $68 \%$ underestimated the time to onset of action. While $62 \%$ correctly identified the number of doses of ipratropium bromide, $25 \%$ incorrectly endorsed twice the recommended dosage (36\% of physicians versus $6 \%$ of allied professionals; $\mathrm{P}=0.03$ ). There was no group difference in other outcomes. Most of the respondents recognized the importance of early administration for both oral corticosteroids and anticholinergics.

With regard to attitude, more than $90 \%$ of all respondents strongly agreed with the use of clinical practice guidelines in the ED, the severity-specific asthma guidelines and the recommended management of mild and moderate asthma (Table 2). More than 20\%, however, disagreed with the pathway for severe asthma, usually advocating the need for individualized care of these patients. Almost all respondents acknowledged that the advantages of providing pathway-based care outweighed the disadvantages, mostly stating improved care and reduced admissions as well as harmonization of care as a rationale for supporting the pathway. Similarly, almost all respondents reported that they were comfortable using the PRAM severity score. There were no statistically significant differences between physicians and allied health care professionals in their attitudes toward the pathway.

Care pathway use is presented in Table 3. Although 83\% of health care professionals reported 'almost always' adhering to the pathway, approximately two-thirds reported making variations. The proportion of pathway variations using additional therapy increased with asthma severity. Frequently reported reasons for pathway variations were the need to account for patients' response to therapy and practical issues such as the patient vomiting the medication. The PRAM was the most frequently used index for assessing severity, yet there was a significant group difference in the distribution of all the tools used to assess severity $(\mathrm{P}=0.04)$. In addition, nurses and respiratory therapists reported using the PRAM at each assessment significantly more frequently than physicians $(100 \%$ versus $74 \% ; \mathrm{P}=0.001$ ). While the target delay for administering medications was generally adequate, allied health professionals reported unnecessarily administering ipratropium bromide to patients with mild and moderate asthma significantly more often than physicians $(\mathrm{P}<0.01)$.

Seventy-seven per cent of the health care professionals surveyed responded to the open-ended questions regarding barriers to implementation. Health care professionals tended to report internal barriers as reasons for deviating from recommended medications, whereas external barriers were more likely cited for not meeting the time guidelines (administration of treatment within $1 \mathrm{~h}$ of triage). With regard to following the treatment plan, each barrier was cited only once, with the exception of the following: the need to adjust to patients' response to treatment $(n=9)$; physicians overriding the pathway $(n=4)$; the belief that the PRAM does not always correlate with the perceived global assessment $(n=3)$; preference to use clinical judgement when making treatment decisions $(\mathrm{n}=2)$; physicians' slow acceptance of routine use of systemic corticosteroids $(\mathrm{n}=2)$; and miscommunication among the three types of health care professionals $(n=2)$. With regard to meeting the time guidelines, commonly cited barriers included the following: overcrowding in the $\mathrm{ED}(\mathrm{n}=19)$; demands of other patients $(\mathrm{n}=7)$; difficulty identifying the attending physician $(\mathrm{n}=3)$; delay in physicians' assessment of patient $(n=2)$; and the inability of nurses to administer treatment beyond initial bronchodilators without a prescription $(n=2)$. Physicians tended to report more internal barriers to following the treatment plan than nurses and respiratory therapists.

\section{DISCUSSION}

We surveyed emergency health care professionals in an effort to understand the knowledge, attitudes and behaviours that explained suboptimal adherence to our acute asthma care pathway. Almost all health care professionals reported being 
TABLE 1

Familiarity with the asthma pathway and pharmacokinetics of selected asthma medications

\begin{tabular}{|c|c|c|c|}
\hline & \multirow[b]{2}{*}{ Total $(n=72)$} & \multicolumn{2}{|c|}{ Health care professionals } \\
\hline & & Physicians $(n=47)$ & Allied* $(n=25)$ \\
\hline Familiarity with the pathway (yes response) & $99(96-100)$ & $98(94-100)$ & 100 \\
\hline Pediatric Respiratory Assessment Measure cut-off value for moderate asthma & $(n=58)$ & $(n=39)$ & $(n=19)$ \\
\hline$\leq 4$ & $35(22-47)$ & $31(16-45)$ & $42(20-64)$ \\
\hline 5 & $53(41-66)$ & $59(44-74)$ & $42(20-64)$ \\
\hline$\geq 6$ & $12(5-23)$ & $10(0-20)$ & $16(3-32)$ \\
\hline$\leq 8$ & $61(48-73)$ & $56(37-67)$ & $68(42-71)$ \\
\hline 9 & $36(24-49)$ & $41(26-56)$ & $26(7-46)$ \\
\hline$\geq 10$ & $3(0-8)$ & $3 \%(0-16)$ & $6(2-10)$ \\
\hline \multicolumn{4}{|l|}{ Mechanism of action ${ }^{\dagger}$} \\
\hline Salbutamol & $(n=67)$ & $(n=46)$ & $(n=21)$ \\
\hline Relieve bronchospasm & $4(0-9)$ & $2(0-6)$ & $10(1-21)$ \\
\hline Relieve airway inflammation & $97(91-100)$ & $98(94-100)$ & $95(79-98)$ \\
\hline Ipratropium bromide & $(n=65)$ & $(n=44)$ & $(n=21)$ \\
\hline Relieve bronchospasm & $91(84-97)$ & $95(91-100)$ & $81(70-90)$ \\
\hline Relieve airway inflammation & $32(17-36)$ & $23(10-33)$ & $52(30-55)$ \\
\hline \multicolumn{4}{|l|}{ Onset of action of the following: } \\
\hline Salbutamol & $(n=66)$ & $(n=45)$ & $(n=21)$ \\
\hline $0 \mathrm{~min}$ to $30 \mathrm{~min}$ & $98(96-100)$ & $98(93-100)$ & 100 \\
\hline $60 \mathrm{~min}$ to $90 \mathrm{~min}$ & $2(0-4)$ & $2(0-7)$ & - \\
\hline Oral prednisone & $(n=64)$ & $(n=43)$ & $(n=21)$ \\
\hline \multicolumn{4}{|l|}{ Timing of medications } \\
\hline Oral prednisone & $(n=67)$ & $(n=46)$ & $(n=21)$ \\
\hline Early is better & $96(91-100)$ & $96(90-100)$ & $95(86-100)$ \\
\hline Later is better & $1(0-4)$ & $2(0-6)$ & - \\
\hline Timing does not matter & $3(0-7)$ & $2(0-6)$ & $5(1-24)$ \\
\hline Ipratropium bromide & $(n=62)$ & $(n=46)$ & $(n=21)$ \\
\hline Early is better & $81(71-90)$ & 78 (65-91) & $86(71-100)$ \\
\hline Later is better & $2(0-5)$ & $2(0-7)$ & - \\
\hline Timing does not matter & $17(8-27)$ & $20(7-32)$ & $14(1-29)$ \\
\hline Recommended ipratropium bromide dose & $(n=44)$ & $(n=28)$ & $(n=16)$ \\
\hline $250 \mu \mathrm{g}$ & $75(62-88)$ & $64(47-82)$ & $94(70-99)$ \\
\hline$\geq 500 \mu \mathrm{g}$ & $25(12-38)$ & $36(18-53)$ & $6(0-18)$ \\
\hline Doses, $\mathrm{n}$ & $(n=52)$ & $(n=36)$ & $(n=16)$ \\
\hline$<2$ & $38(25-52)$ & $44(28-61)$ & $25(5-46)$ \\
\hline 3 & $62(48-75)$ & $56(39-72)$ & $75(54-96)$ \\
\hline Timing from triage & $(n=53)$ & $(n=37)$ & $(n=16)$ \\
\hline$\leq 60 \mathrm{~min}$ & $98(94-100)$ & 100 & $93(70-99)$ \\
\hline$>60 \min$ & $2(0-6)$ & - & $7(1-18)$ \\
\hline
\end{tabular}

Data presented as \% (95\% Cl). Correct answers, where applicable, are shaded in grey. ${ }^{*}$ Allied health care professionals include nurses and respiratory technicians; ${ }^{\dagger}$ Categories are not mutually exclusive and total response may exceed $100 \%$ 
TABLE 2

Attitudes toward the asthma pathway and its recommendations

\begin{tabular}{|c|c|c|c|}
\hline & \multirow[b]{2}{*}{ Total $(n=72)$} & \multicolumn{2}{|c|}{ Health care professionals } \\
\hline & & Physicians $(n=47)$ & Allied* $(n=25)$ \\
\hline Use of pathways in the emergency department in general & $97(93-100)$ & $96(90-100)$ & 100 \\
\hline Severity-specific treatment & $(\mathrm{n}=70) / 96(91-100)$ & $(n=46) / 98(94-100)$ & $(n=24) / 92(81-100)$ \\
\hline Use of the asthma pathway for the following: & $(n=70)$ & $(n=44)$ & $(n=24)$ \\
\hline Mild asthma ${ }^{\dagger}$ & $91(84-98)$ & 89 (79-98) & $96(88-100)$ \\
\hline Moderate asthma & $(n=68) / 94(86-96)$ & $(n=43) / 93(85-100)$ & $(n=24) / 96(88-100)$ \\
\hline Perceived advantages $\$$ & $(n=72)$ & $(n=47)$ & $(n=25)$ \\
\hline Improved care and reduced admissions & $82(73-92)$ & $85(75-95)$ & $76(59-93)$ \\
\hline Harmonized care & $81(70-89)$ & $83(72-94)$ & $76(59-93)$ \\
\hline Reduced hospital stay & $60(48-71)$ & $55(41-70)$ & $68(50-86)$ \\
\hline Other" & $30(19-40)$ & $26(13-39)$ & $36(17-55)$ \\
\hline Restriction on physician's liberty & $11(4-18)$ & $11(2-19)$ & $12(0-24)$ \\
\hline Other** & $19(10-29)$ & $17(6-28)$ & $24(7-41)$ \\
\hline \multicolumn{4}{|c|}{ Comfort level with using the Pediatric Respiratory Assessment Measure } \\
\hline Quite comfortable & $92(85-98)$ & $89(81-98)$ & $96(88-100)$ \\
\hline Comfortable & $6(0.2-11)$ & $6(0-13)$ & $4(0-12)$ \\
\hline Somewhat comfortable & $2(0-7)$ & $4(0-10)$ & - \\
\hline
\end{tabular}

Data presented as \% $(95 \% \mathrm{Cl}) .{ }^{*}$ Allied health care professionals include nurses and respiratory technicians; ${ }^{\dagger}$ Reasons for disagreement included recommendations for repeat salbutamol inhalations after the initial hour of treatment and the time commitment of following the pathway; ${ }^{\ddagger}$ Reason for disagreement was that these patients require individualized care; ${ }^{\S}$ Categories are not mutually exclusive and total response may exceed 100\%; "Other perceived advantages of the pathway were as follows: allowed for earlier administration of medication, ensured accountability, helped nurses anticipate physicians' prescriptions, gave nurses and respiratory technicians more autonomy and provided an assessment tool for severity; ${ }^{\star *}$ Other perceived disadvantages included initiation of the asthma pathway in cases for which the diagnosis was unclear or not confirmed, lack of flexibility to manage disease according to its progression, poor applicability of the asthma pathway to manage very severe or very mild cases, unproven validation (in 2006) of using the Pediatric Respiratory Assessment Measure in children older than preschool school age, no room to record clinical remarks and reduced active thinking on the part of trainees

familiar and agreeing with the severity-specific pathway and the PRAM severity index, indicating high perceived selfefficacy with both. However, two-thirds of respondents admitted to creating variations to the care pathway, usually adding medications and providing more intensive treatment than recommended for patients with higher severity. Moreover, health care professionals identified lower than recommended PRAM cut-offs for moderate and severe asthma. The latter two behaviours would lead to more aggressive treatment than recommended, which contradicts previous observations of undertreatment for most patients with moderate or severe asthma in the same institution $(7,8)$. The results highlight the ongoing dilemma between standardization and the individualization of care, with the latter still being favoured among emergency health care professionals at the Montreal Children's Hospital after four years of implementation.

Although health care professionals reported high familiarity with the pathway, their knowledge of specific details such as the PRAM cut-offs, the onset of action of oral corticosteroids and ipratropium bromide, and the dose of ipratropium bromide, was suboptimal. Perception of a more rapid onset of action of oral corticosteroids and ipratropium bromide may explain, in part, the delayed use of these medications. While periodical refresher seminars may be an option, attendance may be low given that the health care professionals surveyed perceived themselves to be knowledgeable of the pathway details. Perhaps, compulsory refresher sessions incorporating feedback on knowledge of and adherence to the pathway would offer health care professionals a realistic picture of their actual knowledge and behaviour. Interestingly, one-third and two-thirds of health care professionals, respectively, used lower PRAM cut-off scores to define moderate and severe asthma. Were respondents unable to remember the PRAM cut-offs, which are available at the time of care anyway? Did the respondents not agree with them and reported the PRAM cut-off values they use, suggesting the need to re-examine the PRAM cut-offs? In fact, based on rates of admission associated with PRAM score at triage, a subsequent study (21) suggested that PRAM cut-off values should be lowered by 1 point to 4 rather than 5 , and 8 rather than 9 for moderate and severe asthma, respectively. Thus, with these changes, $13 \%$ of respondents would have used lower PRAM cut-off values than recommended. In this case, use of slightly lower cut-off values was actually more appropriate.

Overwhelmingly, doctors, nurses and respiratory therapists held positive attitudes and beliefs toward the care pathway. Our respondents can be classified as 'intenders' - individuals who have the intention of performing a particular behaviour (23). Unfortunately, intention does not necessarily translate into actual practice. In fact, a systematic review (23) revealed that $47 \%$ of intenders fail to act on their intentions, usually 
TABLE 3

Self-reported use of the asthma pathway

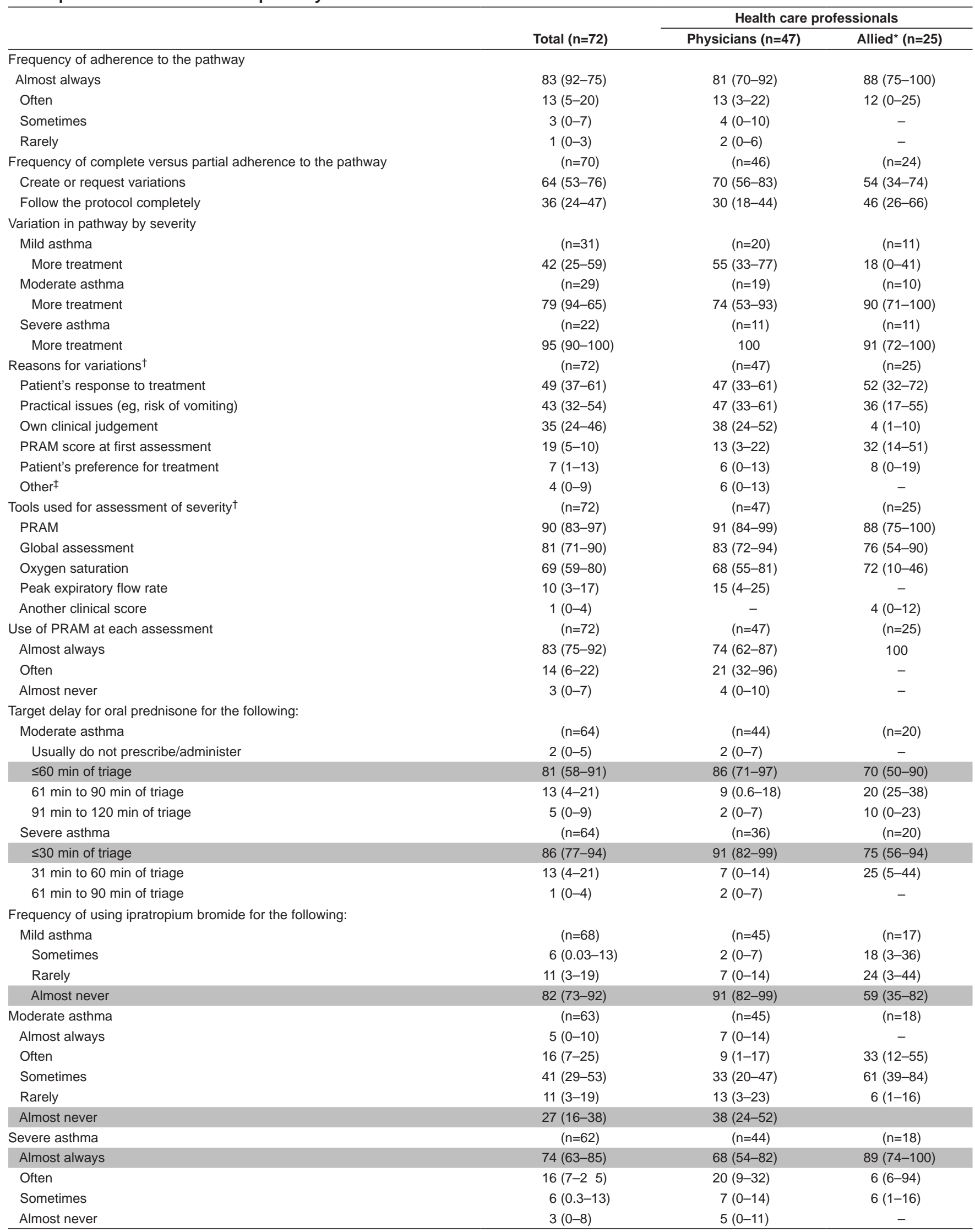

Data presented as \% (95\% Cl). Correct answers, where applicable are shaded in grey. *Allied health care professionals include nurses and respiratory technicians; ${ }^{\dagger}$ Categories are not mutually exclusive and total response ( $n$ and \%) may exceed the total number surveyed; ${ }^{\ddagger}$ Other reasons for creating variations to the asthma protocol included duration of illness before the emergency visit. PRAM Pediatric Respiratory Assessment Measure 
because of forgetfulness or obstacles to implementation. The present study highlighted the conflict between the desire to standardize versus individualize care, as well as several barriers to implementation, including knowledge of the pathway and the perceived importance of adapting treatment to patient response. As we did for the PRAM cut-off values, our results suggest that it is important to examine whether health outcomes are improved if response to treatment is incorporated into the pathway. Clearly, better understanding of the barriers and solutions are required to bridge the intention-behaviour gap.

With respect to behaviour, most of our respondents reported being adherent to the guideline, although two-thirds also reported creating or requesting variations to the pathway, with even more describing the variations they made. Indeed, guidelines are intended to be just that - a guide, not a rule - because clinically, they are only one option for improving quality of care (24). The optimal balance between standardization and individualization of care for acute pediatric asthma patients is not known. Health care professionals indicated a preference for making treatment decisions based on their assessment of patient need. Most reported using more intensive treatment than recommended. The tendency to err on the side of overtreatment would probably be better than undertreatment for cases involving acute exacerbation of asthma. Interestingly, self-reported use of treatment by the health care professionals conflicts with the observed low adherence in our setting, in which only approximately $40 \%$ of moderate and severe asthma patients receive timely treatment with systemic corticosteroids $(7,8)$. This may reflect a misperception of one's own practice or the tendency to decrease therapy in the presence of a good response to initial treatment. While adaptation is done in good faith, the benefit to patients of individualized versus standardized care is called into question and should be explored.

The survey's open-ended questions intended to provide us with a general overview of some of the barriers to pathway adherence. Most barriers to pathway uptake were internal, while barriers to timely administration of medications were external. Consistent with other studies, physicians tended to mention internal barriers while allied health care professionals tended to refer to external barriers $(25,26)$. This is likely a reflection of current practice (ie, role distribution) where physicians decide on the treatment and allied health care professionals administer the prescribed therapy.

Our study is strengthened by its multidisciplinary, representative sample population, which included all levels of health care professionals involved in the management of acute asthma (physicians, nurses and respiratory therapists) who cared for $77 \%$ of patients with acute asthma during the study period. The present study must, however, be interpreted in light of the following limitations. First, with a $56 \%$ response rate, it is possible that a selection bias occurred. However, the absence of significant differences in the basic characteristics between respondents and nonrespondents was somewhat reassuring. Second, there was an under-representation of nurses who are primarily responsible for initiating treatment at triage. The combination of a nursing shortage and rotating shifts, in the absence of protected time to complete the survey, made it difficult to distribute and receive completed questionnaires to and from all eligible nurses. Third, it is possible that reported knowledge was overestimated because theoretically, all respondents had direct access to the care pathway when completing the survey. Fourth, a social desirability bias may have led some health care professionals to report more favourable attitudes and behaviour toward the pathway than those actually held. Finally, due to the anonymous nature of the survey, we were unable to validate reported versus documented adherence. Our survey was conducted in a single tertiary care pediatric ED; the results may not be generalizable to other institutions or settings.

\section{CONCLUSION}

The results of our survey suggest that four years after implementation, the clear intention of almost all health care professionals is to adhere to the acute asthma care pathway. Barriers to implementation reported by physicians included gaps in the knowledge of the severity score, drugs and dosage, disagreement with certain elements of the protocol, with suggestions for improvement and, importantly, the struggle between the proper balance between individualization versus standardization of care. A sizable list provides some interesting leads of external barriers to implementation. While surveys can provide important preliminary information, focus groups may generate insight into barriers and help prioritize solutions to bridge the intention-behaviour gap in the management of acute pediatric asthma.

CONFLICT OF INTEREST: The authors report no conflict of interest. This manuscript is part of a PhD thesis by Sanjit K Bhogal. An editor was remunerated to review the final draft of the manuscript.

AUTHORS' CONTRIBUTIONS: SKB conceived the study in collaboration with FMD and DM. SKB participated in its design and coordination, was involved with the analyses of barriers and interpretation of results, and with writing of the manuscript. JB, FMD and DM participated in the study design and drafting of the survey questions, and were involved with the interpretation of results and writing of the manuscript. $\mathrm{SJB}$ and $\mathrm{AB}$ assisted in the interpretation of results and review of the manuscript. All coauthors approved of the final manuscript.

ACKNOWLEDGEMENTS: Special acknowledgements to Michel Martin and Benjamin Crulli for their help with the distribution and collection of the surveys, Robert Rodriguez for his help with using the ED log, Anjeet Bhogal for her help with proofreading the manuscript, and Danielle Buch for editing the final manuscript. SKB and DM are members, and FMD was a member of the Research Institute of the McGill University Health Centre; FMD is a member of the Research Centre of the Centre hospitalier universitaire Ste-Justine (Montreal, Quebec). Both centres are supported in part by the Fonds de la recherche en santé du Québec.

FUNDING: This study was fully funded by the Research Institute at the Montreal Children's Hospital.

\section{REFERENCES}

1. Rowe BH, Spooner C, Ducharme FM, Bretzlaff JA, Bota GW. Early emergency department treatment of acute asthma with systemic corticosteroids. Cochrane Database Syst Rev 2001;(1):CD002178. 
2. Plotnick LH, Ducharme FM. Combined inhaled anticholinergics and beta2-agonists for initial treatment of acute asthma in children. Cochrane Database Syst Rev 2000; (4):CD000060.

3. Browne GJ, Giles H, McCaskill ME, Fasher BJ, Lam LT. The benefits of using clinical pathways for managing acute paediatric illness in an emergency department. J Qual Clin Pract 2001;21:50-5.

4. Norton SP, Pusic MV, Taha F, Heathcote S, Carleton BC. Effect of a clinical pathway on the hospitalisation rates of children with asthma: A prospective study. Arch Dis Child 2007;92:60-6.

5. Wazeka A, Valacer DJ, Cooper M, Caplan DW, DiMaio M. Impact of a pediatric asthma clinical pathway on hospital cost and length of stay. Pediatr Pulmonol 2001;32:211-6.

6. Sucov A, Veenema TG. Implementation of a disease-specific care plan changes clinician behaviors. Am J Emerg Med 2000;18:367-71.

7. McGillivray D, Chalut D, Plotnick L, Savdie C, Kudirka D, Ducharme F. Use of an emergency department (ED) asthma order sheet to increase adherence to evidence-based guidelines: An interventional trial. (Abst 641) <http://www.abstracts2view. $\mathrm{com} /$ pasall/search.php?query=McGillivray\& where[]=author\&intMa $\mathrm{xHits}=10$ \& search $=$ do $>$ (Accessed on July 27, 2010).

8. Bhogal SK, Bourbeau J, McGillivray D, Benedetti A, Bartlett S, Ducharme F. Determinants of delayed administration of systemic steroids in acute childhood asthma. Am J Respir Crit Care Med 2008;17:A299. (Abst)

9. Reynolds BC, Beattie TF, Cunningham S. The impact of national guidelines on the assessment and management of acute paediatric asthma presenting at a tertiary children's emergency department. Eur J Emerg Med 2007;14:142-6.

10. Scribano PV, Lerer T, Kennedy D, Cloutier MM. Provider adherence to a clinical practice guideline for acute asthma in a pediatric emergency department. Acad Emerg Med 2001;8:1147-52.

11. Freeman AC, Sweeney K. Why general practitioners do not implement evidence: Qualitative study. BMJ 2001;323:1100-2.

12. Straus SE, McAlister FA. Evidence-based medicine: A commentary on common criticisms. CMAJ 2000;163:837-41.

13. Cabana MD, Rand CS, Powe NR, et al. Why don't physicians follow clinical practice guidelines? A framework for improvement. JAMA 1999;282:1458-65.

14. Cabana MD, Rand CS, Becher OJ, Rubin HR. Reasons for pediatrician nonadherence to asthma guidelines. Arch Pediatr Adolesc Med 2001;155:1057-62.
15. Formoso G, Liberati A, Magrini N. Practice guidelines: Useful and "participative" method? Survey of Italian physicians by professional setting. Arch Intern Med 2001;161:2037-42.

16. Farquhar CM, Kofa EW, Slutsky JR. Clinicians' attitudes to clinical practice guidelines: A systematic review. Med J Aust 2002;177:502-6.

17. Cabana MD, Ebel BE, Cooper-Patrick L, Powe NR, Rubin HR, Rand CS. Barriers pediatricians face when using asthma practice guidelines. Arch Pediatr Adolesc Med 2000;154:685-93.

18. International consensus report on diagnosis and treatment of asthma. National Heart, Lung, and Blood Institute, National Institutes of Health. Bethesda, Maryland 20892. Publication no. 92-3091, March 1992. Eur Respir J 1992;5:601-41.

19. Global strategy for asthma management and prevention, 2009 (update). <http://www.ginasthma.com/index.asp?11=1\&12=0> (Accessed on July 27, 2010).

20. Beveridge RC, Grunfeld AF, Hodder RV, Verbeek PR. Guidelines for the emergency management of asthma in adults. CAEP/CTS Asthma Advisory Committee. Canadian Association of Emergency Physicians and the Canadian Thoracic Society. CMAJ 1996;155:25-37.

21. Ducharme FM, Chalut D, Plotnick L, et al. The Pediatric Respiratory Assessment Measure: A valid clinical score for assessing acute asthma severity from toddlers to teenagers. J Pediatr 2008;152:476-80.

22. Espeland A, Baerheim A. Factors affecting general practitioners' decisions about plain radiography for back pain: Implications for classification of guideline barriers - a qualitative study. BMC Health Serv Res 2003;3:8.

23. Sheeran P. Intention-behavior relations: A conceptual and empirical review. Eur Rev Social Pyschol 2002;12:1-36.

24. Woolf SH, Grol R, Hutchinson A, Eccles M, Grimshaw J. Clinical guidelines: Potential benefits, limitations, and harms of clinical guidelines. BMJ 1999;318:527-30.

25. Degeling P, Maxwell S, Kennedy J, Coyle B. Medicine, management, and modernisation: A "danse macabre"? BMJ 2003;326:649-52.

26. McDonald R, Waring J, Harrison S, Walshe K, Boaden R. Rules and guidelines in clinical practice: A qualitative study in operating theatres of doctors' and nurses' views. Qual Saf Health Care 2005;14:290-4. 


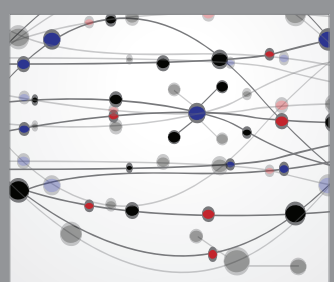

The Scientific World Journal
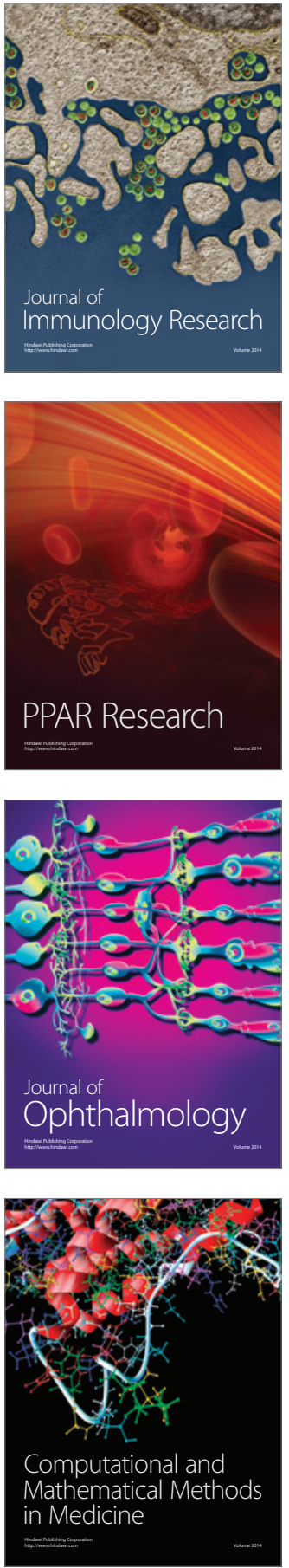

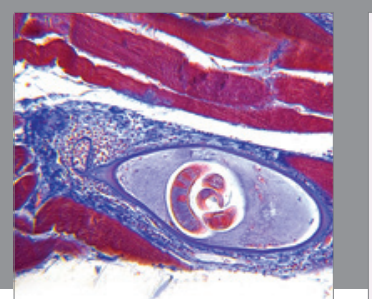

Gastroenterology Research and Practice

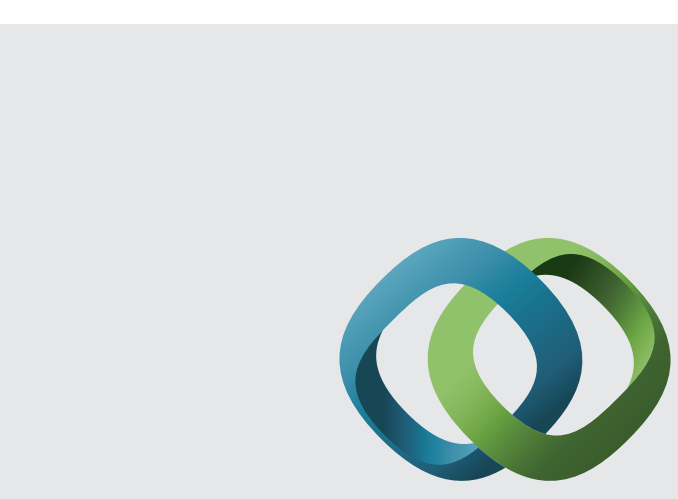

\section{Hindawi}

Submit your manuscripts at

http://www.hindawi.com
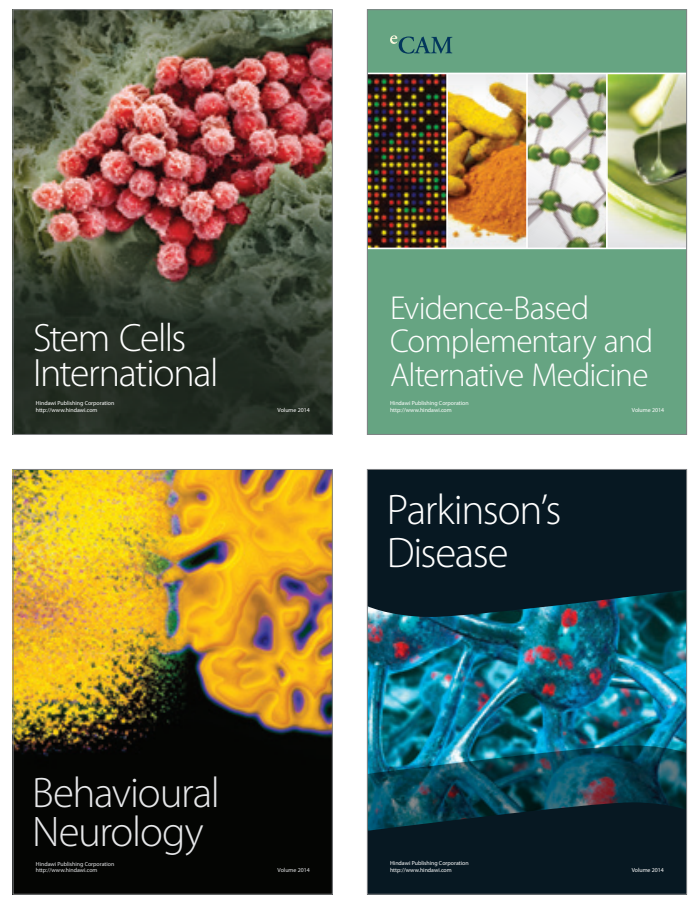
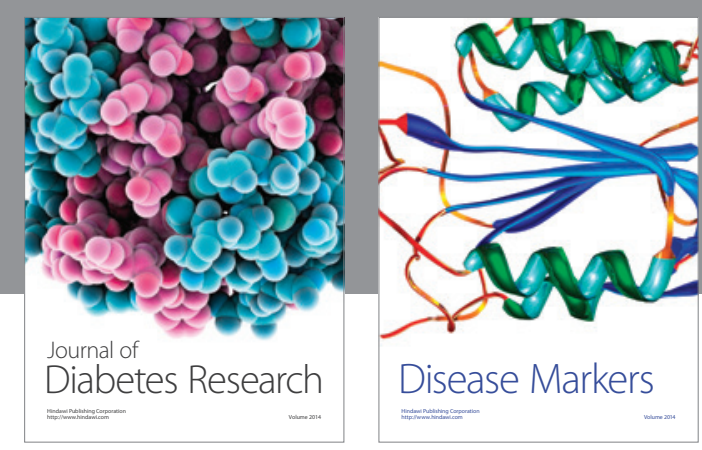

Disease Markers
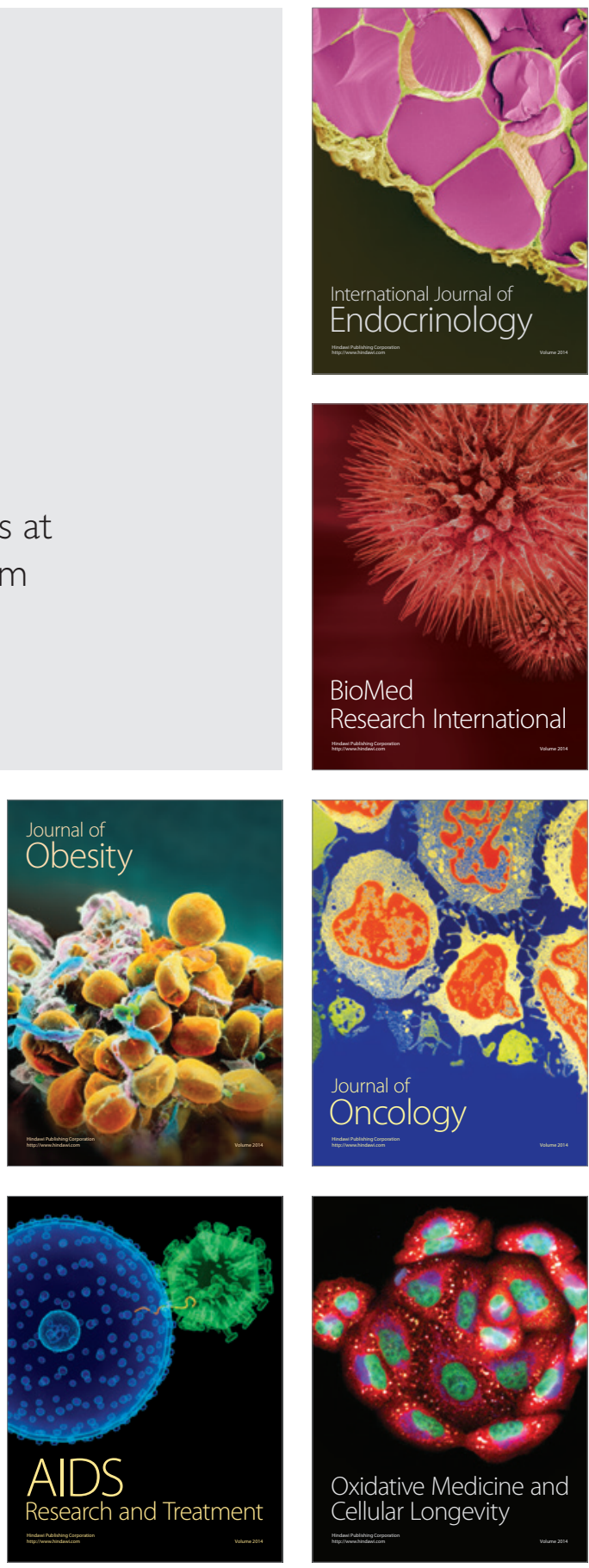